\title{
Chemicals Compositions, Antioxidant and Anti-Inflammatory Activity of Cynara scolymus Leaves Extracts, and Analysis of Major Bioactive Polyphenols by HPLC
}

\author{
Maryem Ben Salem, ${ }^{1}$ Hanen Affes, ${ }^{1}$ Khaled Athmouni, ${ }^{2}$ Kamilia Ksouda, ${ }^{1}$ Raouia Dhouibi, \\ Zouheir Sahnoun, ${ }^{1}$ Serria Hammami, ${ }^{1}$ and Khaled Mounir Zeghal ${ }^{1}$ \\ ${ }^{1}$ Laboratory of Pharmacology, Faculty of Medicine of Sfax, University of Sfax, Sfax, Tunisia \\ ${ }^{2}$ Laboratory of Faculty of Sciences of Sfax, University of Sfax, Sfax, Tunisia \\ Correspondence should be addressed to Hanen Affes; affeshanen13@yahoo.fr
}

Received 20 December 2016; Accepted 19 February 2017; Published 30 April 2017

Academic Editor: Valeria Sulsen

Copyright ( 2017 Maryem Ben Salem et al. This is an open access article distributed under the Creative Commons Attribution License, which permits unrestricted use, distribution, and reproduction in any medium, provided the original work is properly cited.

\begin{abstract}
Objective. Artichoke (Cynara scolymus L.) was one of the plant remedies for primary health care. The present study was focused on the determination of chemical composition, antioxidant activities, and anti-inflammatory activity and on analyzing its major bioactive polyphenols by HPLC. Methods. Artichoke Leaves Extracts (ALE) were analyzed for proximate analysis and phytochemical and antioxidant activity by several methods such as DDPH, ABTS, FRAP, and beta-carotene bleaching test. The carrageenan (Carr) model induced paw oedema in order to investigate the anti-inflammatory activity. Identification and quantification of bioactive polyphenols compounds were done by HPLC method. The oxidative stress parameters were determined; CAT, SOD, GSH, MDA, and AOPP activities and the histopathological examination were also performed. Results. It was noted that EtOH extract of ALE contained the highest phenolic, flavonoid, and tannin contents and the strongest antioxidants activities including DDPH (94.23\%), ABTS (538.75 mmol), FRAP assay (542.62 umol), and $\beta$-carotene bleaching (70.74\%) compared to the other extracts of ALE. Administration of EtOH extract at dose $400 \mathrm{mg} / \mathrm{kg} / \mathrm{bw}$ exhibited a maximum inhibition of inflammation induced by Carr for 3 and 5 hours compared to reference group Indomethacin (Indo). Conclusion. ALE displayed high potential as natural source of minerals and phytochemicals compounds with antioxidant and anti-inflammatory properties.
\end{abstract}

\section{Introduction}

The inflammation reaction is a physiologic response of the body contributed by aggression of microorganism and other soluble products. Polynuclear neutrophils (PN) play an important role in the initiation of inflammation with other molecules named inflammatory mediators released by several cells like cytokines, endotoxins, leukotrienes, prostaglandins, and reactive oxygen species (ROS) [1]. In the beginning for the inflammation reaction, the accumulation of $\mathrm{PN}$ in the inflammatory site and tissue and different cell injury are due to participation of proteolysis' enzymes and ROS by activating defense systems [1].

Oxidative stress is a consequence of discrepancy balance between the production of ROS and antioxidants in a system of defense of human organisms [2]. Several studies showed that many of antioxidants systems have the ability to treat some disease like a cancer by scavenging ROS resultant by oxidative stress systems [3].

Carr induced paw oedema model is used to assess the different phases of inflammation reaction. Carr model can induce acute inflammation, release of inflammatory mediators, and production of free radicals [4].

The mechanism of antioxidant enzymatic systems against the inflammatory stress includes superoxide dismutase (SOD), catalase (CAT), and nonenzymatic antioxidants as reduced glutathione (GSH). Recently, several studies showed that lack of antioxidant systems can cause many inflammatory diseases [5]. However, it showed that various roles of enzymatic and nonenzymatic antioxidants help to protect 
organisms from excessive generation of ROS in the inflammatory states. Some studies showed that natural herbs could suppress the production of oxidative stress by increasing the antioxidants systems [6]. Plants have rich source of phenolic compounds, carotenoids, vitamins, and terpenoids. These compounds have a potential antioxidant that can be free radical scavenger in order to reduce the development of oxidative stress in many diseases [7].

In order to enhance the Tunisian forest resources and develop new products, we are interested in the family of Asteraceae, particularly Cynara scolymus, which characterizes the Mediterranean region and it has been widely used in various hepatic diseases [8].

The objective of this work is designed to evaluate the phytoconstituents of ALE in vitro and the potential antiinflammatory role of ALE in animal's models.

\section{Materials and Methods}

2.1. Plant Material and Extraction Method. C. scolymus dried leaves were obtained from the region of Bizerte in north of Tunisia; the period of collection was December to March 2014. The plant was authenticated by the Laboratory of Biology and Vegetable Ecophysiology in the Faculty of Science of Sfax. The voucher sample was created by The National Botanical Research Institute of Tunisia. Tunisia. Dried powdered plant material $(200 \mathrm{~g}$ ) was extracted by maceration method (1L) using different increasing solvent polarities (hexane, butanol, ethyl acetate, $75 \% \mathrm{EtOH} / \mathrm{H}_{2} \mathrm{O}$, and aqueous). After 48 hours, all extracts were filtered. Then the dried extracts of artichoke were kept in the dark at $+4^{\circ} \mathrm{C}$ in order to evaluate the composition of $C$. scolymus leaves extracts.

2.2. Phytochemical Analysis of Cynara scolymus Leaves Extracts. The analytical tests for identification of different secondary metabolites in Cynara leaves extracts were conducted following procedures described by Sofwora and Okwu $[9,10]$.

2.3. Proximate Analysis of Dried Leaves of C. scolymus. The determination of nutritional composition, crude protein, lipids, fiber, and ash, was obtained using several methods described while the carbohydrate content was obtained by the difference method (calculated by subtracting the sum of crude fat, crude protein, ash content, and crude fiber) [11].

For the determination of crude protein, the concentration of dried samples was determined by micro-Kjeldahl method. The lipid content was estimated by using petroleum ether as a solvent extraction in a Soxhlet at $40-60^{\circ} \mathrm{C}$ [12]. Total dietary fiber was determined by extraction with petroleum ether. The defatted sample was boiled under reflux with two solvents $\mathrm{H}_{2} \mathrm{SO}_{4}$ and $\mathrm{NaOH}$, and then they were filtered and washed with boiling water till the filtrates were no longer acidic and basic. The residue of the sample was dried in an oven at $100^{\circ} \mathrm{C}$ and $600^{\circ} \mathrm{C}$, cooled in desiccators, and weighed [13]. The ash content was estimated by heating in a muffle furnace at $600^{\circ} \mathrm{C}$.

The quantification of dry matter was performed using one gram of C. scolymus leaves heated in $105^{\circ} \mathrm{C}$ for 1 hour. Then, it was put in desiccators for $30 \mathrm{~min}$. After that, the mass of each content has been noticed. These steps have led to dry leaves and their mass has been noticed again in order to calculate the percentage of humidity in these samples [11]. In addition, the analysis of sugar amounts was obtained by phenol-sulfuric acid reagent [14].

2.4. Quantification of Total Phenolics, Flavonoids, and Tannins Contents of Cynara scolymus Leaves Extracts. The quantification of total phenolics content (TPC) of ALE was determined by Fawole et al. method [15]. $200 \mu \mathrm{L}$ of ALE was mixed with $1 \mathrm{~mL}$ of Folin-Ciocalteu reagent diluted $(\times 10)$ with distillated water and $0.8 \mathrm{~mL}$ of $7.5 \%$ of $\mathrm{NaCO}_{3}$ solution in a test tube. $30 \mathrm{~min}$ later, the absorbance was measured at $765 \mathrm{~nm}$ by using a Jenway 6405 UV-Vis spectrophotometer. TPC was expressed as milligrams of gallic acid equivalents per gram of dry weight (mg GA/g DW). Quantification of total flavonoid content (TFC) was determined spectrophotometrically [16]. $500 \mu \mathrm{L}$ of ALE was mixed with $1500 \mu \mathrm{L}$ of water and $150 \mu \mathrm{L}$ of $(5 \%) \mathrm{NaNO}_{2}$. After $5 \mathrm{~min}, 150 \mu \mathrm{L}$ of $\mathrm{ALCl}_{3}(10 \%, \mathrm{~m} / \mathrm{v})$ was added to mixture. After $6 \mathrm{~min}$ of incubation at room temperature, a volume of $500 \mu \mathrm{L}$ of $\mathrm{NaOH}(4 \%)$ was added also. Immediately, the mixture was completely agitated in order to homogenize the contents. The absorbance of solution obtained was measured at $510 \mathrm{~nm}$ against a blank. These analyses were expressed as $\mathrm{mg}$ of catechin equivalents per gram of dry weight (mg CE/g DW).

The determination of condensed tannin content (TCC) was measured using vanillin method [17]. $50 \mu \mathrm{L}$ of ALE diluted was added to mixture which was made of $3 \mathrm{~mL}$ of $4 \%$ methanol-vanillin solution and $1.5 \mathrm{~mL}$ of concentrated $\mathrm{H}_{2} \mathrm{SO}_{4}$. The mixture was incubated to stand for $15 \mathrm{~min}$ and the absorbance was measured at $500 \mathrm{~nm}$ against methanol as a blank. The amount of TCC was expressed as mg catechin equivalent $\mathrm{g}^{-1}$ dry weight (mg CE/g DW).

2.5. Minerals Contents Analysis. The preparation of C. scolymus dried leaves was incinerated in a muffle furnace at $550^{\circ} \mathrm{C}$ for 8 hours [18] and the ashes obtained were digested in nitric acid and dissolved in distilled water for the mineral composition of artichoke leaves [19,20]. Minerals elements of C. scolymus leaves were potassium (K), magnesium (Mg), calcium $(\mathrm{Ca})$, sodium $(\mathrm{Na})$, iron $(\mathrm{I})$, manganese $(\mathrm{Mn})$, zinc $(\mathrm{Zn})$, copper $(\mathrm{Cu})$, and chromium $(\mathrm{Cr})$. These mineral contents were determined by flame atomic absorption spectrometry (Hitachi Z-6100, Japan).

\subsection{Analysis In Vitro of Antioxidants Properties}

2.6.1. Antioxidant Activity by DPPH Method. The antioxidant activity of DPPH is based on scavenging of DPPH' from antioxidants in the vegetal sample, which produce a spectrophotometric loss in absorbance at $515 \mathrm{~nm}$. The DPPH assay (Sigma Chemical Co., St. Louis, MO) was evaluated as described by Fawole et al. [15]. The mixture was prepared in test tubes by dilution of $50 \mathrm{uL}$ of ALE in $735 \mathrm{~mL}$ of $100 \%$ methanol.

$750 \mathrm{~mL}$ of $0.1 \mathrm{mM}$ methanolic DPPH reagent was added to the mixture of ALE-methanol. Then, the mixture was incubated at room temperature in a chamber without any 
light during $30 \mathrm{~min}$. After incubation, the estimation of the scavenging ability was performed by measuring at $517 \mathrm{~nm}$ in spectrophotometer (T70 UV-Vis).

The capacity of inhibition percentage (PI) of $\mathrm{DPPH}$ radicals was calculated as

$$
\mathrm{DPPH} \text { radicals }(\mathrm{PI})=\left[\frac{\left(A_{b}-A_{s}\right)}{A_{b}}\right] \times 100,
$$

where $A_{b}$ refers to the absorbance of control (without plant extract) and $A_{s}$ to the absorbance of sample (with plant extract). BHT and VC were used as standards at the same concentrations of plant extract.

2.6.2. $\beta$-Carotene Bleaching Test. The capacity of ALE to reduce bleaching of beta-carotene was previously determined by Koleva et al. [21]. The mixture of beta-carotene and linoleic acid was prepared; $0.5 \mathrm{mg}$ of $\beta$-carotene, $25 \mathrm{uL}$ of linoleic acid, and $200 \mathrm{uL}$ of Tween 40 were dissolved in $1 \mathrm{~mL}$ of chloroform solvent. The chloroform was evaporated in a rotator evaporator at $40^{\circ} \mathrm{C}$ and $100 \mathrm{~mL}$ of $\mathrm{dH}_{2} \mathrm{O}$ was added; then the mixture was stirred.

Aliquots of $2.5 \mathrm{~mL}$ of beta-carotene/linoleic acid emulsion obtained were transferred to test tubes containing different ALE concentrations; then the emulsion of reaction was incubated for $2 \mathrm{~h}$ at $50^{\circ} \mathrm{C}$ and the absorbance of each sample was measured at $470 \mathrm{~nm}$ by spectrophotometer. BHT and AA were used as the standards at the same concentrations of the samples.

2.6.3. Antioxidant Activity by $A B T S^{\bullet+}$ Method. The ability to neutralize the $\mathrm{ABTS}^{\bullet+}$ was reported by $\mathrm{Re}$ et al. [22] using a spectrophotometric, 96-well microplate method. The preparation of $\mathrm{ABTS}^{\circ}$ free radical solution by incubating a mixture of ABTS $(7 \mathrm{mM})$ and $\mathrm{K}_{2} \mathrm{~S}_{2} \mathrm{O}_{8}(2.45 \mathrm{mM})$ dissolved in distillated water to create a stable color of radical solution following $12-16 \mathrm{~h}$ of incubation in the dark room at $4^{\circ} \mathrm{C}$.

Therefore, the standard $\mathrm{ABTS}^{\bullet+}$ solution was prepared by dilution with ethanol to a standard absorbance of $0.7 \pm 0.02$ at $734 \mathrm{~nm}$.

$50 \mu \mathrm{L}$ of plant extract $(1-20 \mu \mathrm{g} / \mathrm{mL})$ was added to $150 \mu \mathrm{L}$ of $\mathrm{ABTS}^{\circ+}$. The plates were incubated at room temperature, in the dark room during $15 \mathrm{~min}$; the absorbance was measured at $630 \mathrm{~nm}$. Control wells contained $50 \mu \mathrm{L}$ of $\mathrm{H}_{2} \mathrm{O}$ and $150 \mu \mathrm{L}$ of $\mathrm{ABTS}^{\bullet+}$. Phytochemical interference was accounted by wells containing extract $(50 \mu \mathrm{L})$ with $\mathrm{dH}_{2} \mathrm{O}(150 \mu \mathrm{L})$, whereas $200 \mu \mathrm{L}$ of $\mathrm{H}_{2} \mathrm{O}$ served as blank. Trolox dissolved in pure $\mathrm{MeOH}$ was used as standards.

The antioxidant capacity of ALE was expressed quantitatively as mmol of Trolox Equivalents (TE) (mmol TE/g dry extract).

2.6.4. Ferric Reducing Assay. The potential ability of ALE to reduce the ferric iron was evaluated previously by Fawole et al. [15].

The mixture of FRAP was freshly prepared by $50 \mathrm{~mL}$ of $300 \mathrm{mM}$ acetate buffer, $5 \mathrm{~mL}$ of $10 \mathrm{mM}$ TPTZ, and $5 \mathrm{~mL}$ of $20 \mathrm{mM} \mathrm{FeCl}_{3}$. Prior to its use, the prepared mixture must be incubated in water bath at $37^{\circ} \mathrm{C}$ during $15 \mathrm{~min}$ to stabilize the contents in the reaction mixture.
Exactly, $150 \mathrm{~mL}$ of diluted ALE was transferred into different test tubes and then $250 \mathrm{~mL}$ of FRAP solution was added in triplicate. The mixture was stirred and incubated in a dark room for $30 \mathrm{~min}$ before measuring the absorbance at $515 \mathrm{~nm}$ in UV-Vis spectrophotometer. Antioxidant capacity of ALE was expressed as micromoles of Trolox Equivalent per milliliter of sample (mMTE/mL).

\subsection{Anti-Inflammatory Activity In Vivo}

2.7.1. Chemicals and Reagents. Lambda carrageenan and Indomethacin were purchased from Sigma Aldrich company (France).

2.7.2. Experimental Study. 30 sexually mature male rats, 10-12 weeks old weighing 150-200 g, were obtained from the Institute of Pasteur, Tunisia. Rats were fed with standard laboratory pellets and ad libitum access during the experiment study. The experimental protocol was conducted in accordance with the Guide for the Care and Use of Laboratory Animals issued by the University of Sfax, Tunisia, and approved by the Ethics Committee of Animal use, protocol number 94-1939. Before the experiment, rats were acclimatized in controlled environmental conditions at $24 \pm$ $4^{\circ} \mathrm{C}$ with relative humidity (45-55\%) and $12 \mathrm{~h}$ dark-light cycle. All the groups of animals were randomly divided into the control group and treatment groups.

2.7.3. Carrageenan-Induced Paw Oedema Model. The evaluation of anti-inflammatory activity was reported by Ravi et al. [23]. $0.1 \mathrm{~mL}$ of Carr solution (1\%) was injected into subplantar surface of the paw of each group of rats to produce acute inflammation. This method was chosen over other methods for the discovery of new therapeutic effects of ALE in inflammation diseases, as it is the most basic method requiring minimal equipment, but much practice.

The experimental study designed 4 groups of six rats. Group (I) was the control group which received isotonic saline solution $\mathrm{Nacl}(0,9 \%)$ by subplantar injection and had no inflammation and received no treatment. Group (II) was inflamed by carrageenan injection and did not undergo any treatment (Carr). Group (III) was used as reference inflamed rats that were treated with Indomethacin $(10 \mathrm{mg} / \mathrm{kg} / \mathrm{bw})$ (Carr + Indo) by intraperitoneal injection (i.p.) and Group (IV) was treated with EtOH extract of ALE at dose $400 \mathrm{mg} / \mathrm{kg} / \mathrm{bw}$ (Carr+ ALE) by i.p. [24]. The doses of ALE and Indo chosen during treatments were proportional to the size of the oedema and covered the whole swelling.

In all treated groups, the oedema paw volumes, up to tibiotarsal articulation, were measured using a digital caliper at 1, 2, 3, 4, and 5 hours after Carr injection.

For each treated group, the size of oedema obtained at these various times (PT) was compared to that obtained before any treatment $(\mathrm{P} 0)$.

Percentages of oedema inhibition were calculated as

$$
\% \text { Inhibition }(\mathrm{EI})=\left[1-\left(\frac{\mathrm{PT}}{\mathrm{P} 0}\right)\right] \times 100 \text {. }
$$


TABLE 1: Phytochemical analysis of Cynara scolymus extracts leaves.

\begin{tabular}{lcccccc}
\hline Extract & Cardiac glycosides & Triterpenoids & Saponin & Flavonoids & Tannins & Alkaloid \\
\hline ALE & + & + & + & + & + & + \\
\hline
\end{tabular}

Sign (+) indicates being present.

Percentages of inflammation inhibition were calculated as

$$
\% \text { Inhibition }(\mathrm{II})=\left[\mathrm{PT}-\left(\frac{\mathrm{P} 0}{\mathrm{P} 0}\right)\right] \times 100 \text {. }
$$

2.7.4. Blood Sample Collection. 5 hours after Carr induction, the rats were decapitated and the blood samples were collected in heparin tubes. Plasma samples were obtained after centrifugation at $3000 \mathrm{rpm}$ for $15 \mathrm{~min}$ and they were kept in $-20^{\circ} \mathrm{C}$ until analysis on an automatic biochemistry analyzer at the biochemical laboratory of Hedi Chaker Hospital of Sfax.

\subsubsection{Inflammatory Biomarkers}

(1) Determination of C-Reactive Protein (CRP). CRP was a specific marker following the inflammatory process. It increases in proportion to its intensity [25]. The reactive protein was measured by turbid metric method using an automatic analyzer COBAS INTEGRA 400" C-reactive. The CRP is expressed with $\mathrm{mg} / \mathrm{L}$.

(2) The Fibrinogen Assay of Plasma. Plasma fibrinogen concentration was determined by Clauss clotting method [26] measured on a STA ${ }^{\circledR}$ analyzer. Principle test measures the conversion rate of fibrinogen into fibrin in diluted sample in presence of excess of thrombin and records the clotting time. The clotting time is inversely proportional to the level of fibrinogen in the plasma. The fibrinogen level is expressed with g/L plasma.

(3) Exploring the Antioxidant Enzymatic and Nonenzymatic Status. Oxidative stress parameters were determined in tissues paw oedema homogenates. The supernatants obtained were removed and analyzed for the determination of MDA as described by Draper and Hadley [27]. AOPP levels were quantified by method of Kayali et al. [28]. CAT activity was measured as reported by Aebi [29] and expressed as mmoles of $\mathrm{H}_{2} \mathrm{O}_{2}$ consumed/(min/mg protein). SOD was assayed spectrophotometrically by colorimetric method of Beyer Jr. and Fridovich [30] and expressed as U/mg protein. GSH activity was assayed according to the method of Carlberg and Mannervik [31] and expressed as mmoles GSS/(min$\mathrm{mg}$ protein) and the protein content was determined using method of Lowry et al. [32].

(4) Histopathological Examination. All the paws oedema tissues of experimental groups were collected for histological examination. First, they were fixed in $10 \%$ buffered formalin solution; second, they were embedded in paraffin wax and then cut into $5 \mathrm{~mm}$ thick sections and stained with hematoxylin and eosin (H\&E). Finally, the slides were photographed with an Olympus U-TU1X-2 camera.
2.8. High Performance Liquid Chromatography (HPLC) Detection and Quantification of Polyphenolic Compounds. The phenolic fractions analysis of EtOH extract of ALE was determined using an Agilent Technologies 1100 series HPLC coupled with a UV-Vis multiwavelength detector. The separation was carried out on a $250 \times 4.6 \mathrm{~mm}$. C18 silica column chromatography was chosen at ambient temperature. The mobile phase consisted of $\mathrm{C}_{2} \mathrm{H}_{3} \mathrm{~N}$ (solvent $\mathrm{A}$ ) and water with $0.2 \%$ of $\mathrm{H}_{2} \mathrm{SO}_{4}$ (solvent $\mathrm{B}$ ) and the flow rate was kept at $0.8 \mathrm{~mL} \mathrm{~min}^{-1}$. For the preparation of calibration curve, a standard stock solution was prepared in methanol (HPLC grade $\geq 99.9 \%$ from Sigma Chemical Company) containing Hydroxytyrosol, Tyrosol, 4-hydroxybenzoic acid, verbascoside, apigenin-7-glucoside, Oleuropein, Quercetin, Pinoresinol, cinnamic acid, and apigenin at the same concentration of $1 \mathrm{~g} / \mathrm{mL}$. For the preparation of the ethanol extract by dissolving in $1 \mathrm{~mL}$ of methanol making a final concentration of $25 \mathrm{mg} / \mathrm{mL}$. Before starting HPLC analysis, all the solutions prepared were filtered with Whatman paper $(\varnothing 0.45 \mu \mathrm{m})$. The diluted extract was injected directly and chromatograms were monitored at $280 \mathrm{~nm}$. $20 \mu \mathrm{L}$ was used for injection. Peaks were identified by the retention times compared with the standards. The analyses of phenolic profiles of ethanol extract were performed in triplicate.

2.9. Statistical Analysis. SPSS program was employed for comparisons between all groups. Comparison between multiple and within groups was analyzed by ANOVA followed by Tukey's tests. Values were shown as mean \pm SD. The level of statistical significance was set at $p$ value $<0.05$. Pearson's correlation coefficient analysis was calculated using SPSS program also in order to evaluate the statistical relationship between both of polyphenolics compounds and antioxidant activities of ALE.

\section{Results}

3.1. Phytochemical Analysis of Cynara scolymus Leaves Extracts. ALE revealed the presence of flavonoid, cardiac glycosides, saponin, tannin, terpenoid, and alkaloids (Table 1).

3.2. Proximate Analysis of Dried Leaves of C. scolymus. The results showed that Cynara leaves contain high constituents: dry matter (97,03\% DW), ash $(15,81 \%$ DW), carbohydrate (80,05\% DW), protein (16,64\% DW), lipids (3,41\% DW), total sugars $(1,97 \%$ DW), and dietary fiber $(71,60 \%$ DW) (Table 2$)$.

3.3. Quantification of Total Phenolic, Flavonoid, and Tannins Contents of Cynara scolymus Leaves Extracts. The TPC, TFC, and TCC were evaluated in different solvents extracts of ALE. All results are shown in Table 3. Maximum content of TPC was obtained using EtOH extract and corresponded to 54.54 \pm $1.26 \mathrm{mg} \mathrm{GA} / \mathrm{g}$ DW followed by ethyl acetate, aqueous, and 
TABLE 2: Proximate analysis of dried leaves of Cynara scolymus.

\begin{tabular}{lc}
\hline Constituents & $\begin{array}{c}\text { Cynara scolymus leaves } \\
\text { (percentage dry weight basis) }\end{array}$ \\
\hline Dry matter & $97.03 \pm 0.43$ \\
Ash & $15.81 \pm 0.01$ \\
Carbohydrate & $80.05 \pm 0.69$ \\
Protein & $16.64 \pm 1.79$ \\
Lipids & $3.41 \pm 0.45$ \\
Total sugars & $1.97 \pm 0.10$ \\
Dietary fiber & $71.60 \pm 0.81$ \\
\hline
\end{tabular}

Values are expressed as mean $\pm \mathrm{SD}(n=3)$.

butanol extracts, while TPC of hexane extract was the lowest in comparison with EtOH extract $(30.91 \pm 9.36 \mathrm{mg}$ GAE/g DW). The EtOH extract showed also the highest content in TFC $(12 \pm 0.83 \mathrm{CE} / \mathrm{g} \mathrm{DW})$, but this value was lower for hexane extract $(8.19 \pm 0.6 \mathrm{mg} \mathrm{CE} / \mathrm{g} \mathrm{DW})$, respectively.

The amount of TCC which was evaluated by vanillin assay was the highest in the ethyl acetate and EtOH extract (14.51 and $14.05 \mathrm{mg} \mathrm{CE} / \mathrm{g} \mathrm{DW}$ ), but this content was lower than aqueous extract as shown in Table 3.

3.4. Mineral Contents Analysis. The main composition of macroelements and microelements in C. scolymus leaves is presented in Table 4.

Elemental analysis in ( $\mathrm{mg} / 100 \mathrm{~g}$ of dry weight basis) indicated that leaves of artichoke contained the following order of essential minerals compounds: potassium (2886.80), sodium (1762.94), calcium (1359.34), magnesium (433.21), iron (16.17), manganese (13.05), zinc (7.37), copper (1.30), and chromium (0.12).

3.5. Evaluation of Antioxidant Activity. The antioxidant activity of ALE harvested in Tunisia was performed using four methods: DPPH, ABTS, FRAP, and beta-carotene test.

3.5.1. Antioxidant Activity by DPPH Method. DDPH method evaluated the capacity of compounds present in ALE to reduce DDPH radical. The result in Figure 1 showed the scavenging activity of all extracts of C. scolymus was concentration dependent. Among all extracts, the EtOH extract displayed the highest free radical scavenging activity at higher concentration $(400 \mathrm{ug} / \mathrm{mL})(94.23 \%)$ compared to the same concentration of vitamin C (9.83\%) and BHT (96.23\%) followed by ethyl acetate extract ( $81.51 \%)$; the scavenging activity of other extracts was significantly lower when compared to reference standard VC $(99.83 \%)$.

3.5.2. $\beta$-Carotene Bleaching Test. The potential effect of EtOH extract exhibited significantly the highest inhibition rate of $\beta$-carotene bleaching $(70.74 \%)$ compared to BHT and AA $(47.94 \%, 90.59 \%)(p<0,001)$, respectively (Table 5), whereas hexane and butanol extract showed the lowest rate of $\beta$ carotene bleaching $37.38 \%$ and $49.39 \%$.

3.5.3. Antioxidant Activity by ABTS $^{++}$Method. As evident from Table 5, ALE studied presents a potential capacity

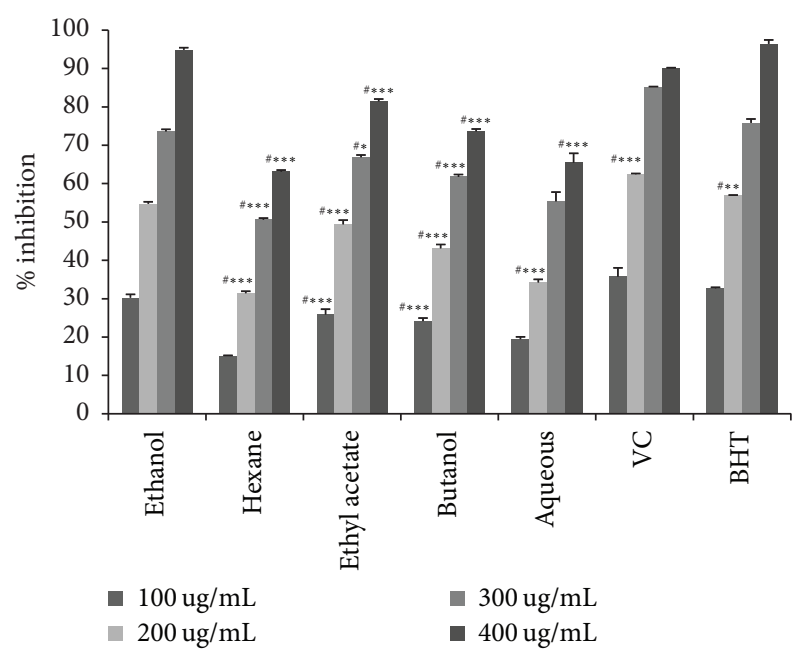

FIGURE 1: Antioxidant activity by DPPH method of Cynara scolymus leaves extracts at different concentrations. Values are mean \pm SD $(n=3) .{ }^{*} p<0.05,{ }^{* *} p<0.01$, and ${ }^{* * *} p<0.001 ;{ }^{*}$ compared to EtOH extract. Butylated Hydroxytoluene (BHT). Vitamin C (VC).

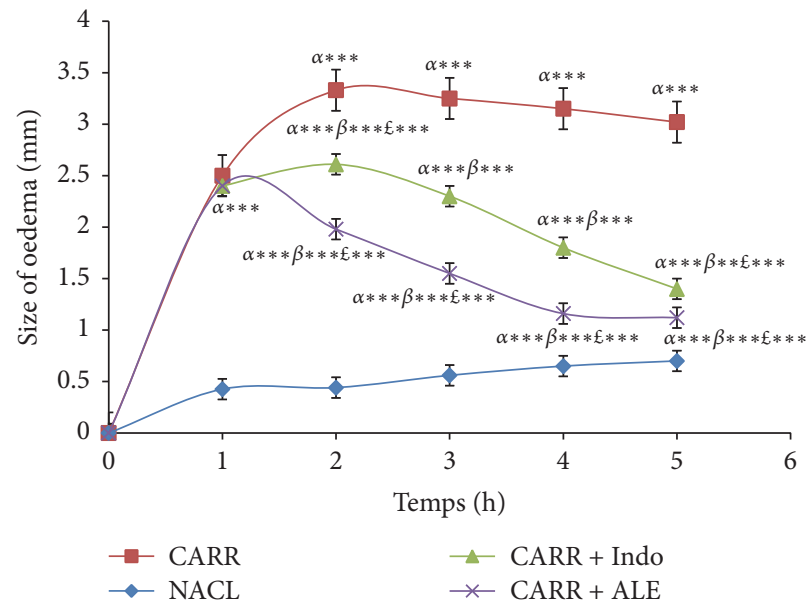

FIGURE 2: Effect of ALE and Indomethacin on paw oedema induced by carrageenan. Values represent mean $\pm \operatorname{SD}(n=6)$ in each group. ${ }^{*} p<0.05,{ }^{* *} p<0.01$, and ${ }^{* * *} p<0.001$. $\alpha$ : compared to control; $\beta$ : compared to Carr; $\mathfrak{E}$ : compared to Carr + Indo.

to scavenge the ABTS radical cation. Among all extracts, $\mathrm{EtOH}$ extract was a significantly higher value $(499.43 \mathrm{mmol}$ Trolox/g dry extract) than the other extracts, but the lowest level of TEAC was obtained from the hexane extract (104.3 mmol Trolox/g dry extract).

3.5.4. Ferric Reducing Assay. The results in Table 5 showed that, among all extracts of ALE, a higher capacity of reducing ferric capacity was found for EtOH extract $(527.79$ umol $\mathrm{Fe}^{2+} / \mathrm{mg}$ dry extract) when compared to other extracts, respectively.

3.6. Anti-Inflammatory Activities. The appearance of Carr induced paw oedema with respective treatments groups was illustrated in Table 7 and Figure 2. The results showed 
TABLE 3: Quantification of total phenolic, flavonoids, and tannins contents of Cynara scolymus leaves extracts.

\begin{tabular}{lccc}
\hline Extracts & $\begin{array}{c}\text { Phenolics content } \\
(\text { mg GAE/g DW) }\end{array}$ & $\begin{array}{c}\text { Flavonoids } \\
\text { content } \\
\text { (mg CE/g DW) }\end{array}$ & $\begin{array}{c}\text { Tannins content } \\
(\mathrm{mg} \mathrm{CE} / \mathrm{g} \mathrm{DW})\end{array}$ \\
\hline Hexane & $39.91 \pm 9.36$ & $8.19 \pm 0.16$ & $14.05 \pm 0.3$ \\
Ethyl acetate & $53.07 \pm 0.47$ & $10.32 \pm 0.12$ & $14.51 \pm 0.13$ \\
Butanol & $41.66 \pm 2.23$ & $11.21 \pm 0.10$ & $13.93 \pm 93$ \\
Ethanol & $54.54 \pm 1.26$ & $12.00 \pm 0.83$ & 10.99 \\
Aqueous & $49.49 \pm 0.39$ & $9.49 \pm 0.39$ & $4.38 \pm 0.45$ \\
\hline
\end{tabular}

Values are expressed as mean $\pm \mathrm{SD}(n=3)$.

TABLE 4: Mineral contents dried leaves of Cynara scolymus.

\begin{tabular}{lc}
\hline Elements & $\begin{array}{c}\text { Cynara scolymus leaves }(\mathrm{mg} / 100 \mathrm{~g} \text { of dry weight } \\
\text { basis })\end{array}$ \\
\hline $\mathrm{K}$ & $2886.803 \pm 12.0$ \\
$\mathrm{Ca}$ & $1359.346 \pm 5.05$ \\
$\mathrm{Na}$ & $1762.946 \pm 12.0$ \\
$\mathrm{Mg}$ & $433.219 \pm 23.4$ \\
$\mathrm{I}$ & $16.176 \pm 0.14$ \\
$\mathrm{Mn}$ & $13.051 \pm 0.11$ \\
$\mathrm{Zn}$ & $7.371 \pm 0.14$ \\
$\mathrm{Copper}$ & $1.30 \pm 0.16$ \\
$\mathrm{Cr}$ & $0.124 \pm 0.01$ \\
\hline
\end{tabular}

Values are expressed as mean $\pm \mathrm{SD}(n=3)$.

that the induction of Carr in rats paw oedema started off by the vascular phase of inflammation which generated an increase in the size of oedema for all groups. This injection generated intense inflammation which peaked after 3 hours. The experimental data showed that ALE presented significant decrease in the size of paw oedema which was time dependent and more important than the reference group Indo and Carr group.

As seen in Figures 3 and 4 , EtOH extract at dose $(400 \mathrm{mg} / \mathrm{kg} / \mathrm{bw})$ has shown a significant percent of oedema inhibition $(p<0.001)$ in the first hour $(17.3 \%)$ compared with reference group (Indo) and the significant percent of inhibition inflammation was $44,27 \%$ in comparison with the control group.

Thus, after five hours, these percentages were $735 \%$ for inhibition and $832 \%$ for inflammation. For the Indo group, oedema inhibition was significant $(p<0,001), 53$ and $64 \%$, and oedema inflammation was 21 and $86 \%$ in comparison with the control group.

These results showed that EtOH extract of ALE had a strong effect as Indo.

3.6.1. Inflammatory Biomarkers: Fibrinogen and CRP. We assayed serum proteins of inflammatory markers in different groups of rats.

(1) Fibrinogen. Carr group caused a significant increase in rate of fibrinogen compared to control group by $19.05 \%$ (Figure 5).

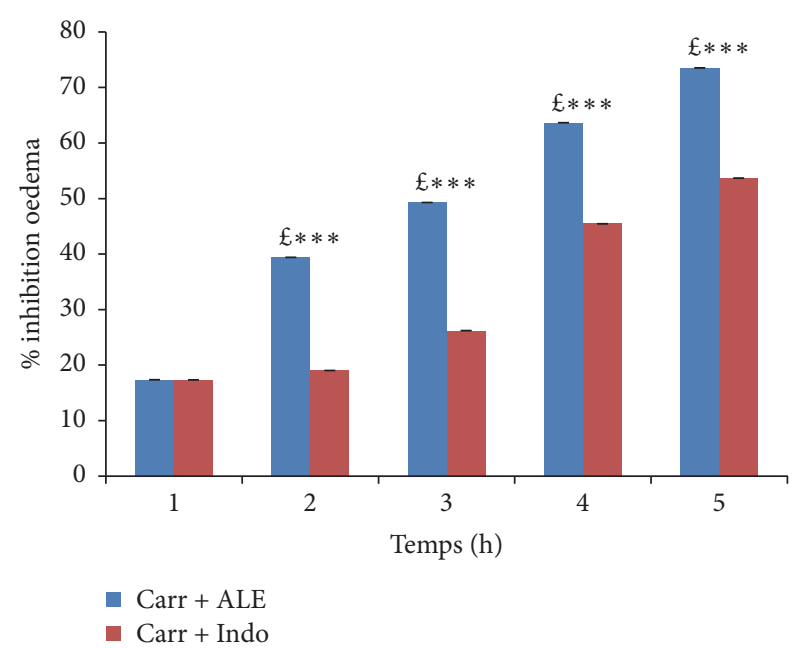

Figure 3: Percentage (\%) of oedema inhibition data in all groups. Values represent mean $\pm \mathrm{SD}(n=6)$ in each group. ${ }^{*} p<0.05,{ }^{* *} p<$ 0.01 , and ${ }^{* * *} p<0.001$. $£$ : compared to Carr + Indo.

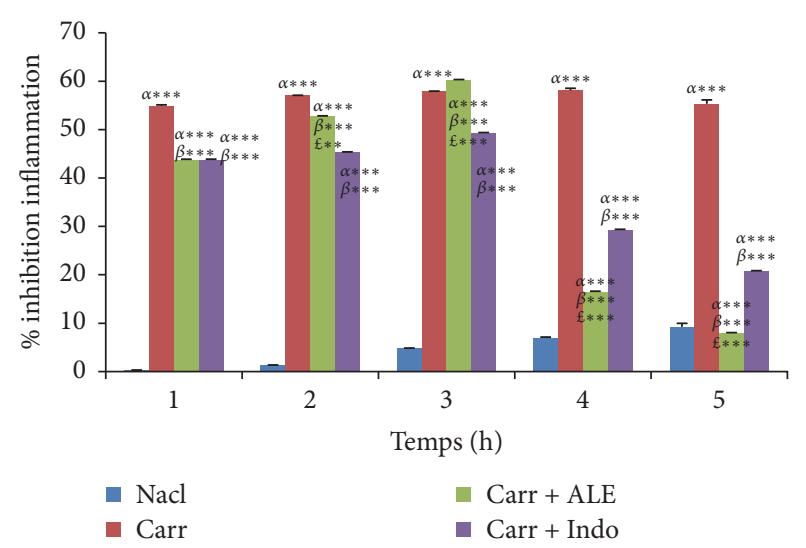

FIGURE 4: Percentage (\%) of oedema inflammation data in all groups. Values represent mean $\pm \mathrm{SD}(n=6)$ in each group. ${ }^{*} p<$ $0.05,{ }^{* *} p<0.01$, and ${ }^{* * *} p<0.001 . \alpha$ : compared to control group, $\beta$ : compared to Carr group, and $\mathfrak{E}$ : compared to Indo group.

The rate of fibrinogen decreased significantly $(p<0.01)$ in groups of rats treated with the EtOH extract $(16.55 \%)$ and Indo $(22.90 \%)$ compared with Carr group. 
TABLE 5: Antioxidant activities of Cynara scolymus leaves extracts.

\begin{tabular}{lccc}
\hline Sample & FRAP assay (umol Fe (II)/g & $\begin{array}{c}\beta \text {-Carotene bleaching assay } \\
(\%)\end{array}$ & $\begin{array}{c}\text { TEAC assay (mmol } \\
\text { Trolox/g DW) }\end{array}$ \\
\hline Hexane & DW) & $37.38 \pm 5.24^{\# * * *}$ & $104.3 \pm 10.73^{\# * * *}$ \\
Ethyl acetate & $223.023 \pm 11.16^{\# * * *}$ & $61.56 \pm 8.17^{\# *}$ & $382.60 \pm 5.24^{\# * *}$ \\
Butanol & $508.29 \pm 5.24^{\# * * *}$ & $49.393 \pm 2.24^{\# * *}$ & $251.93 \pm 28.15^{\# * * *}$ \\
Ethanol & $443.06 \pm 22.98^{\# * * *}$ & $70.743 \pm 1.29$ & $499.43 \pm 39.72$ \\
Aqueous & $527.79 \pm 16.26$ & $56.11 \pm 5.43^{\# * *}$ & $210.74 \pm 8.36^{\# * * *}$ \\
BHT & $315.91 \pm 8.36^{\# * * *}$ & $47.94 \pm 0.75^{\# * * *}$ & - \\
AA & - & $90.59 \pm 3.25^{\# * * *}$ & - \\
\hline
\end{tabular}

Values are means $\pm \mathrm{SD}(n=3)$. Butylated Hydroxytoluene (BHT) and Ascorbic Acid (AA) were used as positive control; ${ }^{\#}$ compared with EtOH extract. ${ }^{*} p<$ $0.05,{ }^{* *} p<0.01$ and $^{* * *} p<0.001$.

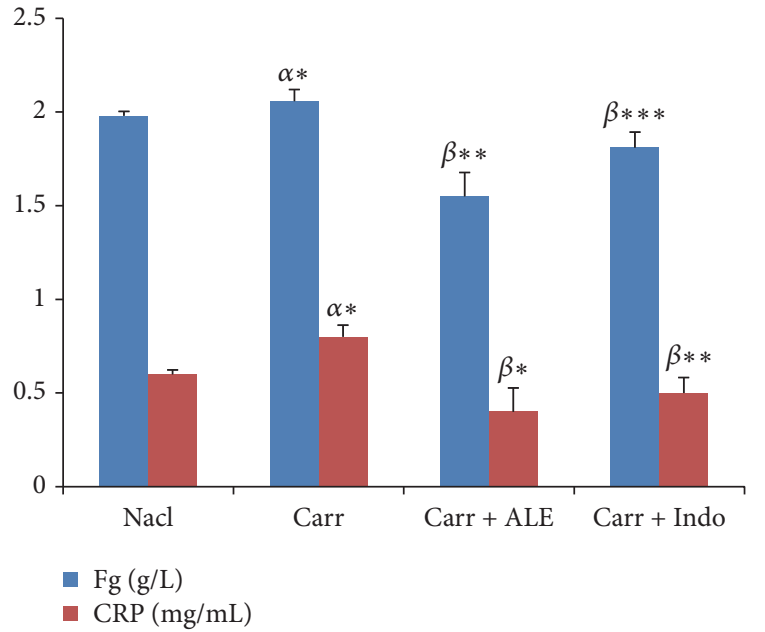

FIGURE 5: Levels of fibrinogen (Fg) and C-reactive protein (CRP). Values represent mean $\pm \mathrm{SD}(n=6)$ in each group. ${ }^{*} p<0.05,{ }^{* *} p<$ 0.01 , and ${ }^{* * *} p<0.001$. $\alpha$ : compared to control; $\beta$ : compared to Carr group. Fibrinogen (Fg). C-reactive protein (CRP).

(2) CRP. Analysis showed a significant increase $(p<0.05)$ in CRP level (Figure 5) for Carr group compared to control group (16.73\%). However, the injection of EtOH extract and Indo led to a significant decrease $(p<0,001)(60.86 \%$, $34.23 \%)$, respectively, when compared with Carr group.

3.7. Oxidative Stress Parameters. MDA and AOPP levels in oedema paw were illustrated in Table 8. Results showed that Carr induced a significant increase in MDA and AOPP levels; however treatment with $\mathrm{EtOH}$ extract of ALE at dose of $400 \mathrm{mg} / \mathrm{kg} / \mathrm{bw}$ showed a significant decrease $(p<0,001)$ $(20.80 \%, 50.23 \%)$, compared with Carr group and even Indo group $(10 \mathrm{mg} / \mathrm{kg})(20.97 \%, 44.27 \%)$, respectively.

3.8. Exploring the Antioxidant Enzymatic and Nonenzymatic Status. CAT, SOD, and GSH levels in the paw oedema tissue of tested groups are shown in Table 8. Treatment of inflamed rats with EtOH extract restored significantly $(p<0.001)$ the SOD activity by $20.75 \%$, the CAT activity by $56.55 \%$, and the GSH activity by $75.66 \%$, respectively, compared to Carr group.
3.9. Histopathological Examination. A microscopic study of paw oedema tissues showed histological changes in Carr group, EtOH extract of ALE $(400 \mathrm{mg} / \mathrm{kg} / \mathrm{pc})$ group, and Indo $(10 \mathrm{mg} / \mathrm{kg} / \mathrm{bw})$ group (Figure 6$)$. In the Carr group, we showed a subcutaneous oedema with infiltration of inflammatory cells, especially polynuclear neutrophils at the site of inflamed tissues, and also the presence of spongy-like appearance in the epidermis ((Figure 6(b)) as compared to control group (Figure 6(a))). The EtOH extract group produced a significant decrease in the number of cellular infiltrates and a significant reduced spongy-like appearance in the epidermis (Figure 6(c)), as did reference drug Indo (Figure 6(d)).

3.10. Quantification of Polyphenolic Compounds by HPLC. To the authors' knowledge, the present study identified and quantified the phenolic compounds of ALE from Tunisian origins. Accordingly, the results obtained so far by FolinCiocalteu needed to be further complemented to qualify phenolic constituents in EtOH extract under investigation.

The findings revealed the presence of seven phenolic compounds, namely, Hydroxytyrosol, verbascoside, apigenin-7-glucoside, Oleuropein, Quercetin, Pinoresinol, and apigenin. HPLC analysis indicated that ALE have significant amount of verbascoside content $38,1 \mathrm{mg} / 100 \mathrm{~g}$ and Quercetin content (19, $2 \mathrm{mg} / 100 \mathrm{~g})$ (Figures 7 and 8 and Table 9).

3.11. Correlation between the Polyphenolic Compounds and Antioxidant Capacity. In order to determine the contribution of the phenolic and flavonoid content in ALE on antioxidant capacity, the Pearson correlation coefficient $(r)$ was determined in Table 6 . The results showed a significant linear correlation between antioxidant activities determined by using DPPH, ABTS, FRAP, and beta-carotene methods and TPC and TFC, respectively. The strongest correlative value is obtained with DDPH and TPC $(r=0.87)$. These results indicated a good correlation between TPC and TFC with antioxidant activities of ALE.

\section{Discussion}

The importance of plants in traditional medicine remedies and the potential of phytochemical constituents were discussed nowadays with respect to their benefit in pharmacotherapy in Tunisia. Cynara scolymus was one of these 

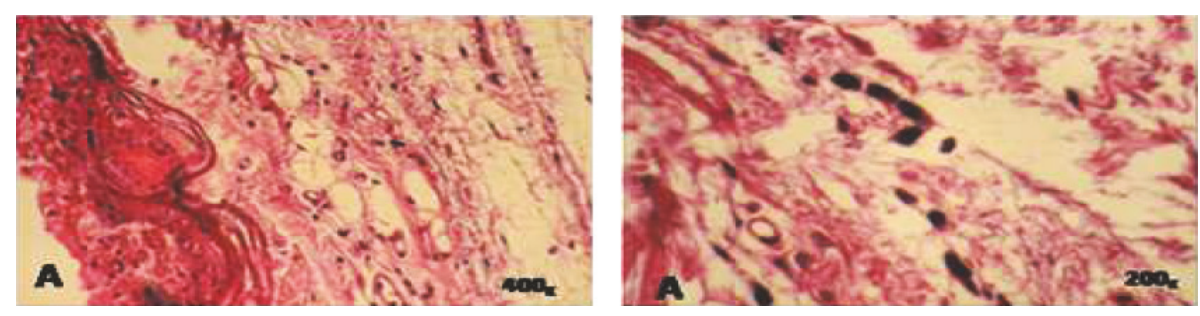

(a)
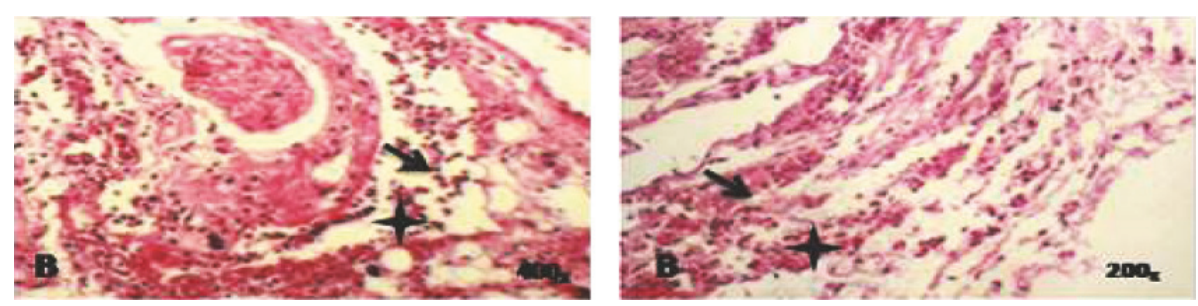

(b)
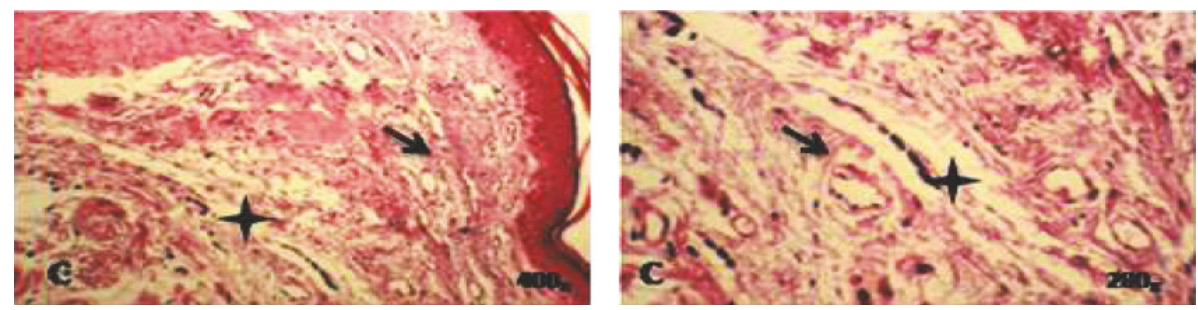

(c)
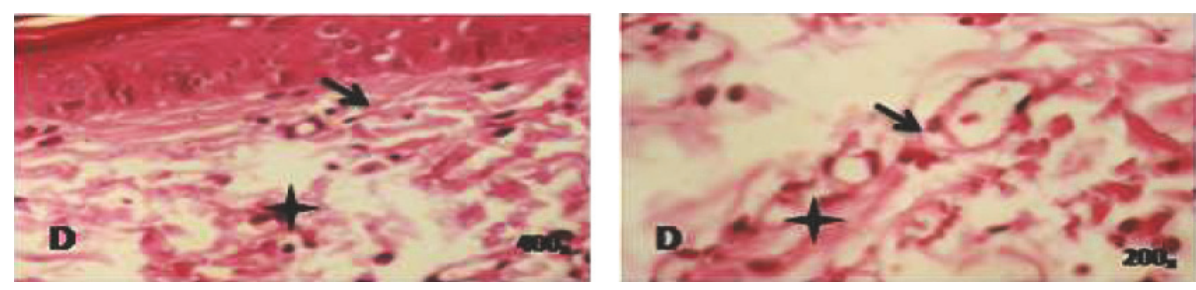

(d)

Figure 6: Histopathological slides tissues of paw oedema in experimental groups of rats. (a) Control group; untreated group. (b) Carr group; Carr-treated rat showed heavy infiltration of polynuclear neutrophils (PN) and a spongy-like appearance and bulla in the epidermis. (c) Carr + EtOH extract group; Carr-treated rat that received the EtOH extract $(400 \mathrm{mg} / \mathrm{kg} / \mathrm{bw})$ reduced significantly the migration of PN and oedematasis in dermis without any spongy-like feature and bulla. (d) Carr + Indo group; Carr-treated rat that received Indomethacin $(10 \mathrm{mg} / \mathrm{kg} / \mathrm{bw})$ showed a partial protective action. Deparaffinized hematoxylin and eosin (H\&E) stained sections (200-400x). Plus sign: infiltration of PN. Arrow: odematasis in the epidermis.

medicinal plants which have a beneficial potential effect attributed to its source of polyphenolic compounds [3].

The selection of this plant was guided by the indications of its traditional use that, at present, there have been very little chemical and biological investigations done. Therefore the present study was to investigate phytochemical composition and their antioxidant capacity and to evaluate in vivo the antiinflammatory effects of Cynara scolymus leaves extracts.

The presence of phenolic compounds is very widely distributed in medicinal plants; several studies showed that these compounds have drawn much attention to their potential antioxidant abilities which demonstrated their beneficial implications for human health.
Regarding the determination of phenolic compounds, the EtOH extract of ALE had the highest amount of these compounds in comparison with other extracts, which were an agreement with the result of Emanue et al. [33], who shows that EtOH extract exhibited the maximum amount of phenolic compounds from the leaves of Cynara scolymus, whereas it differs from the reports of Oliveira et al. [34], who proves that aqueous extract of ALE is the most suitable solvent for extraction of phenolic compounds.

The importance of TPC and TFC extraction yields obtained with $\mathrm{EtOH}$ extract can be attributed to its good solubility, low toxicity, medium polarity, and high extraction capacity [35]. 


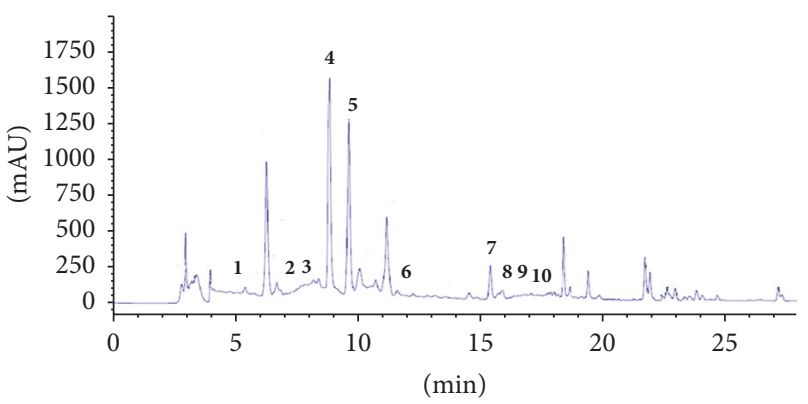

FIGURE 7: HPLC chromatogram of a standard mixture of polyphenolic compounds. Peaks: 1, Hydroxytyrosol; 2, Tyrosol; 3, 4hydroxybenzoic acid; 4, verbascoside; 5, apigenin-7-glucoside; 6, Oleuropein; 7, Quercetin; 8, Pinoresinol; 9, cinnamic acid; 10, apigenin.

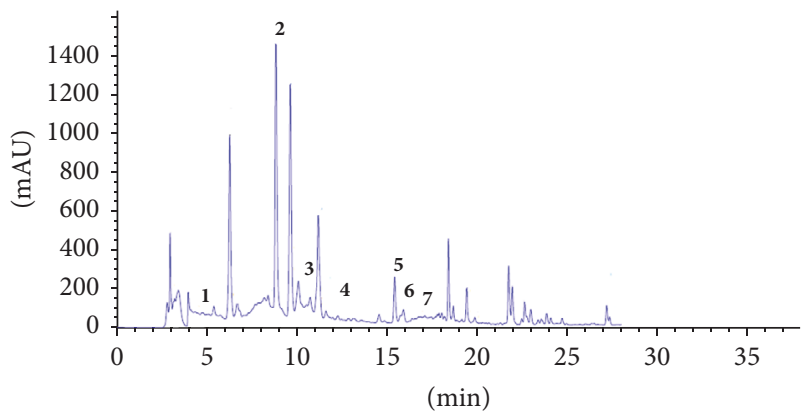

Figure 8: HPLC chromatogram of ethanol extract of Cynara scolymus leaves extracts. Peaks: 1, Hydroxytyrosol; 2, verbascoside; 3, apigenin-7-glucoside; 4, Oleuropein; 5, Quercetin; 6, Pinoresinol; 7 , apigenin.

TABLE 6: Pearson correlation coefficient $(r)$ between the content of phenolic compounds and antioxidant capacity $\left(\mathrm{DDPH}^{\circ}, \mathrm{ABTS}^{\circ+}\right.$, FRAP, and beta-carotene).

\begin{tabular}{lc}
\hline Correlation & $R$ \\
\hline TPC versus DDPH $^{*}$ & $0,870^{* *}$ \\
TPC versus ABTS $^{++}$ & $0,848^{* *}$ \\
TPC versus FRAP & $0,707^{* *}$ \\
TPC versus beta-carotene & $0,842^{* *}$ \\
TFC versus DDPH & $0,728^{* *}$ \\
TFC versus ABTS & \\
TFC versus FRAP & $0,743^{* *}$ \\
TFC versus beta-carotene & $0,849^{* *}$ \\
\hline
\end{tabular}

DPPH: 2,2-diphenyl-1-picrylhydrazyl; $\quad$ ABTS: 2,20-azinobis(3ethylbenzothiazoline-6-sulphonic acid) diammonium salt; FRAP: ferric reducing; TPC: total phenolic content; TFC: total flavonoid content; ${ }^{* *} p<0.01$ significant correlation.

In the first investigation of my study, five solvents of increasing polarities were chosen for the determination of phenolic compounds from leaves of C. scolymus, namely, hexane, ethyl acetate, butanol, $75 \% \mathrm{EtOH} / \mathrm{H}_{2} \mathrm{O}$, and aqueous, in order to determine the variability of TPC and TFC in the aerial part of Cynara as a function of each extraction solvent.
This variability of phenolic compounds in ALE can be attributed to the wide range of solubility displayed by various polar compounds within the ALE solvents, the degree of polymerization of phenols and their interaction, genetic factors, geographical variations, and climatic changes [36].

Overall, these findings indicate that EtOH extract of ALE was rich in phenolic and flavonoid contents, which could be the major contributor to their antioxidative properties. Many researches revealed that flavonoids and polyphenols displayed the highest ability of scavenging activity in medicinal plants [37, 38].

The results indicate that EtOH extract of ALE, which contains the highest content of TFC and TPC, displays the highest free radical scavenging activity $(94.23 \%)$ at concentration of $400 \mathrm{ug} / \mathrm{mL}$. However, Oliveira et al. [34] show that aqueous extract of ALE has good radical scavenging (83.40\%) at concentration of $200 \mathrm{ug} / \mathrm{mL}$. Furthermore, our results suggest that some components within EtOH extract are significantly the strongest radical scavenger in comparison with other extracts. The TEAC values of ALE showed also that $\mathrm{EtOH}$ extract presents a potential ability to scavenge the ABTS radical cation in accordance with the report of Betancor-Fernández et al. [39].

The FRAP assay shows also that EtOH extract has the highest values (542.62 umol Fe II g/DW). The same result is confirmed by Kukić et al. [40]. Therefore, the results of positive correlation between the TPC, TFC, and the antioxidant methods in vitro suggest that phenolic compounds act as reducing agents, hydrogen donors, and singlet oxygen scavengers [3] and may exert an important in vitro antioxidant capacity of ALE.

The phytochemical screening of ALE has been found to be a rich source of polyphenolic compounds including Quercetin, apigenin-7-glucoside, and verbascoside. These compounds have shown a great potential of antioxidant activity [41].

The research into medicinal plants used as pain relievers' agents should therefore be viewed as new therapy in the inflammatory diseases [42]. The anti-inflammatory activities of EtOH extract of ALE are investigated, applying in vivo experimental Carr model compared with a nonsteroidal antiinflammatory (Indomethacin); this drug was reported by Higgs et al. [43] who demonstrated the role of Indo to inhibit the biosynthesis of prostaglandins in Carr model rats. The experimental study of anti-inflammatory activity is performed by the Carr test. This phlogiston agent induced tissue oedema characteristic of acute inflammation which is regarded as a crucial parameter in assessing anti-inflammatory activity [44].

The Carr injection produces biphasic states; in the first phase [45], there is an increase in the mRNA synthesis of cyclooxygenase-2 (COX-2) at the first hour. This increase is accompanied by an amplification of synthesis of strong proinflammatory mediator such as prostaglandin, especially the prostaglandin type 2 involved in the inflammatory process [46], serotonin, bradykinin, and leukotrienes, which contribute to the initiation of inflammation reaction. Moreover, the participation of arachidonic metabolites is the main factor responsible for both of phases of Carr induced inflammation. 


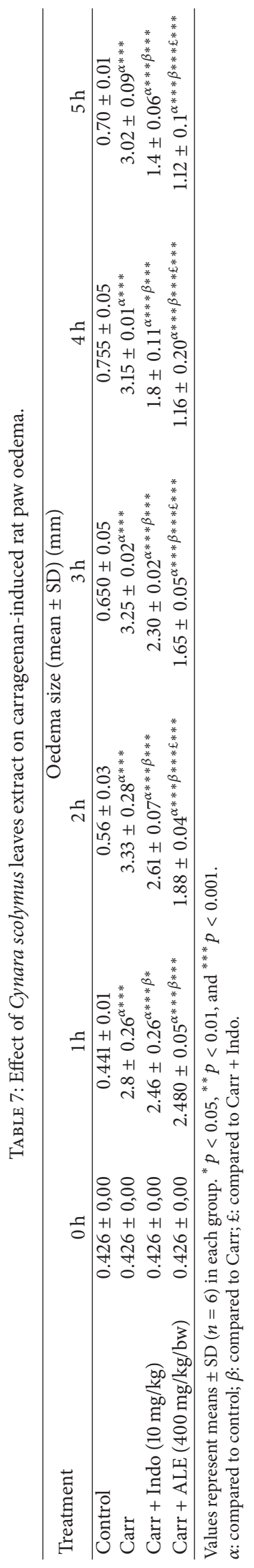


TABLE 8: Effects of Cynara scolymus leaves extract and Indomethacin on CAT, SOD, GSH, AOPP, and MDA activities in carrageenan induced paw oedema.

\begin{tabular}{|c|c|c|c|c|c|}
\hline Groups & $\begin{array}{c}\text { CAT }(\mu \text { moles } \\
\text { CAT } / \mathrm{min} / \mathrm{mg} \\
\text { protein })\end{array}$ & $\begin{array}{l}\text { SOD (unit } \\
\text { SOD/min/mg } \\
\text { protein) }\end{array}$ & $\begin{array}{c}\text { GSH (nmoles/mg } \\
\text { protein) }\end{array}$ & $\begin{array}{c}\text { MDA (nmol } \\
\text { MDA/mg protein) }\end{array}$ & AOPP (nmol/mg protein) \\
\hline Control & $47 \pm 2$ & $13.1 \pm 4.3$ & $42.1 \pm 1.2$ & $23.4 \pm 5$ & $48.4 \pm 4.3$ \\
\hline Carr & $16.2 \pm 0.5^{\alpha * * *}$ & $15.3 \pm 2.6^{\alpha * * *}$ & $13.1 \pm 1.1^{\alpha * * *}$ & $31.4 \pm 7.5^{\alpha * * *}$ & $67.9 \pm 6.9^{\alpha * * *}$ \\
\hline $\begin{array}{l}\text { Carr + Indo } \\
(10 \mathrm{mg} / \mathrm{kg} / \mathrm{bw})\end{array}$ & $64.9 \pm 7.1^{\beta * * *}$ & $24.0 \pm 1.3^{\beta * * *}$ & $70.3 \pm 1.1^{\beta * * *}$ & $20.9 \pm 3.0^{\beta * * *}$ & $44.2 \pm 0.6^{\beta * * *}$ \\
\hline $\begin{array}{l}\text { Carr + ALE } \\
(400 \mathrm{mg} / \mathrm{kg} / \mathrm{bw})\end{array}$ & $56.5 \pm 2.5^{\beta * * * \mathfrak{E * *}}$ & $20.7 \pm 4.0^{\beta * * * £ * *}$ & $75.6 \pm 2.5^{\beta * * * £ *}$ & $20.8 \pm 6.0^{\beta * * *}$ & $50.2 \pm 4.1^{\beta * * * \mathfrak{E *}}$ \\
\hline
\end{tabular}

Values represent means $\pm \mathrm{SD}(n=6)$ in each group. ${ }^{*} p<0.05,{ }^{* *} p<0.01$, and ${ }^{* * *} p<0.001$.

$\alpha$ : compared to control; $\beta$ : compared to Carr; $\mathfrak{E}$ : compared to Carr + Indo.

SOD: superoxide dismutase.

CAT: catalase.

GSH: glutathione peroxidase.

MDA: Malondialdehyde.

AOPP: Advanced Oxidation Protein Product.

TABLE 9: Quantification and identification of phenolic compounds contents in the ethanol extract of Cynara scolymus leaves extracts.

\begin{tabular}{lcc}
\hline Number & Content $(\mathrm{mg} / 100 \mathrm{~g}$ of dry extract $)$ & Polyphenolic compound \\
\hline $\mathbf{1}$ & $2,8 \pm 0,19$ & Hydroxytyrosol \\
$\mathbf{2}$ & $38,1 \pm 0,36$ & Verbascoside \\
$\mathbf{3}$ & $9,9 \pm 0,02$ & Apigenin-7-glucoside \\
$\mathbf{4}$ & $18 \pm 0,1$ & Oleuropein \\
$\mathbf{5}$ & $19,2 \pm 0,14$ & Quercetin \\
$\mathbf{6}$ & $5 \pm 0,05$ & Pinoresinol \\
$\mathbf{7}$ & $4 \pm 0,04$ & Apigenin \\
\hline
\end{tabular}

Values represent means $\pm \mathrm{SD}(n=3)$.

In the second phase, the increase of vascular permeability is observed by release of kinins during $2.30 \mathrm{~h}$. Thereafter from $2.30 \mathrm{~h}$ to $5 \mathrm{~h}$, inflammation is mediated by prostaglandins and is also associated with a release infiltration and migration of $\mathrm{PN}$ into the inflamed site [47].

Our results indicate that ALE affords protection against the Carr induced acute inflammation in dose dependent manner. EtOH extract of ALE at dose of $400 \mathrm{mg} / \mathrm{kg} / \mathrm{bw}$ exhibits significant anti-inflammatory activity with $73 \%$ inhibition of paw oedema compared with Indo group (53\%) and typically reaches a maximum at $5 \mathrm{~h}$; these results obtained suggest the anti-inflammatory effect of EtOH extract of ALE by means of inhibiting the synthesis and the release of inflammatory mediators like histamine, serotonin, and prostaglandins that are involved in acute inflammation. These results revealed the inhibitory effect of EtOH extract on PN migration and it is confirmed through a histological analysis of tissues of paw oedema in experimental groups.

These findings clearly confirm that EtOH extract of ALE has an anti-inflammatory effect by reducing the influx of polymorphonuclear cells to inflammatory tissue following injection of Carr. Most inflammatory markers, such as interleukin-6 (IL-6), tumor necrosis factor- $\alpha$ (TNF- $\alpha$ ), CRP, and fibrinogen, increased significantly in response to infection and in active diseases states. CRP is the specific marker of acute inflammation occurring in the body [48]; moreover the fibrinogen is the most relevant indicator of inflammation, and it does not only represent the acute-phase reactant that is increased in inflammatory states. Elevated fibrinogen levels would be associated with higher levels of CRP and would similarly correlate with inflammation reaction.

Therefore the present study showed that EtOH extract of ALE significantly decreases the level of fibrinogen and CRP by value of $22.72 \%$ and $34.78 \%$ in comparison with Carr group.

The induction of inflammation with Carr is manifested by generation of ROS and has been shown to play an important role in various forms of inflammation $[49,50]$. High concentration of reactive free radicals contributes to lipid peroxidation and protein oxidation [3]. Our results showed that there is a significant increase in MDA and AOPP activities in Carr group, when compared to control group, and a highly significant decrease in activities of SOD, CAT, and GSH, also observed at the tissue level compared with the control group $(p<0.001)$. However, the injection of EtOH extract and Indo shows a significant decrease of the levels of MDA and AOPP by $34.27 \%$ and $44.27 \%$ following a significant increase in antioxidant activities as CAT, SOD, and GSH when compared to Carr group $(20.16 \%, 73.30 \%$, and $75 \%)$. From these results, it is implied that the protective effect of EtOH extract may 
be attributed to its potential indirectly as a stimulator of the activity and expression of antioxidant enzymes during inflammation.

Thus, the anti-inflammatory activity is due to the individual or synergistic effect of the components in the ALE. In fact, previous studies have found that anti-inflammatory profile of ALE could be related to polyphenolic compounds according to the phytochemical analysis. We performed HPLC analysis to justify the correlation between phytochemical compounds and anti-inflammatory activity of this plant. Among these polyphenolic compounds, verbascoside has been reported in several reports and showed a potential spectrum of many activities including antioxidant and anti-inflammatory. Particular, verbascoside presents antiedematogenic activities in animal models of Carr induced inflammation [51] and the responses exhibited the maximum activity for the fourth hour of treatment. Such activities may be derived from inhibitory action of chemical mediators of the inflammatory process such as histamine and bradykinin. A significant antioxidant effect of verbascoside has been recently reported by Aleo et al. [52] in an experimental study [53]. Other authors reported that anti-inflammatory activity of verbascoside has been evaluated by an in vitro test performed on cell cultures of primary human keratinocytes [54] in which it was able to reduce the release of proinflammatory markers such as chemokines.

Apigenin-7-glucoside was found to block the release of several varieties of enzymes involved in inflammation including especially lipoxygenases and cyclooxygenases [55, 56] leading to inhibition of proinflammatory molecules NF$\mathrm{kB}$ activation and inhibits neutrophil infiltration in tissues.

From these results, we suggest that anti-inflammatory activity observed is due to a synergic action of these phenolic components contained in EtOH extract of ALE.

C. scolymus is one of the few herbal remedies which have been verified through experimental studies. Further the toxicity studies of ALE are required in order to confirm the safety of this medicinal plant in the treatment of inflammation diseases.

\section{Conclusion}

The present study showed clearly the advantages of $C$. scolymus leaves extracts which have safer anti-inflammatory profile with potent antioxidant activity attributed to the phenolic compounds. Furthermore, in the future studies, we are interested to characterize the action mechanisms of active phenolic compounds of ALE responsible for antiinflammatory and antioxidants activities.

\section{Conflicts of Interest}

The authors declare no conflicts of interest.

\section{Acknowledgments}

This research was supported by the Tunisian Ministry of Higher Education and Scientific Research.

\section{References}

[1] C. Pasquier, "Stress oxidative et inflammation," Blool, vol. 4, pp. $1-6,1996$.

[2] M. A. Abuashwashi, O. M. Palomino, and M. P. GómezSerranillos, "Geographic origin influences the phenolic composition and antioxidant potential of wild Crataegus monogyna from Spain," Pharmaceutical Biology, vol. 54, no. 11, pp. 27082713, 2016.

[3] M. B. Salem, H. Affes, K. Ksouda et al., "Pharmacological studies of artichoke leaf extract and their health benefits," Plant Foods for Human Nutrition, vol. 70, no. 4, pp. 441-453, 2015.

[4] M.-H. Huang, B.-S. Wang, C.-S. Chiu et al., "Antioxidant, antinociceptive, and anti-inflammatory activities of Xanthii Fructus extract," Journal of Ethnopharmacology, vol. 135, no. 2, pp. 545552, 2011.

[5] G.-J. Huang, S.-S. Huang, S.-S. Lin et al., "Analgesic effects and the mechanisms of anti-inflammation of ergostatrien- $3 \beta$ ol from antrodia camphorata submerged whole broth in mice," Journal of Agricultural and Food Chemistry, vol. 58, no. 12, pp. 7445-7452, 2010.

[6] C. Tohda, N. Nakayama, F. Hatanaka, and K. Komatsu, "Comparison of anti-inflammatory activities of six Curcuma rhizomes: a possible curcuminoid-independent pathway mediated by Curcuma phaeocaulis extract," Evidence-Based Complementary and Alternative Medicine, vol. 3, no. 2, pp. 255-260, 2006.

[7] K. Goksel, K. Murat, Y. Murat, E. Sevil, and H. Fidan, "Antioxidant activities of ethanol extracts of Hypericum triquetrifolium and Hypericum scabroides," Pharmaceutical Biology, vol. 46, no. 4, pp. 231-242, 2008.

[8] R. Gebhardt and M. Fausel, "Antioxidant and hepatoprotective effects of artichoke extracts and constituents in cultured rat hepatocytes," Toxicology in Vitro, vol. 11, no. 5, pp. 669-672, 1997.

[9] A. Sofwora, Medicinal Plants and Traditional Medicine in Africa, John Wiley \& Sons, Ann Arbor, Mich, USA, 1982.

[10] D. E. Okwu, "Phytochemicals, vitamins and mineral contents of two Nigerian medicinal plants," International Journal of Molecular Medicine and Advances Sciences, vol. 1, pp. 375-381, 2005.

[11] N. Tsevegsuren, G. Davaakhuu, and T. S. Udval, "Phytochemical analysis of Cynara scolymus L. cultivated in Mongolia," Mongolian Journal of Chemistry, vol. 15, no. 41, pp. 40-42, 2014.

[12] AACC, Approved Methods of the AACC, American Association of Cereal Chemists, St. Paul, Minn, USA, 8th edition, 1984.

[13] S. C. Lee, L. Prosky, and J. W. DeVries, "Determination of total, soluble, and insoluble, dietary fiber in foods-enzymatic-gravimetric method, MES-TRIS buffer: collaborative study," Journal of the Association of Official Analytical Chemists, vol. 75, pp. 395-416, 1992.

[14] M. Dubois, K. A. Gilles, J. K. Hamilton, P. A. Rebers, and F. Smith, "Colorimetric method for determination of sugars and related substances," Analytical Chemistry, vol. 28, no. 3, pp. 350356, 1956.

[15] O. A. Fawole, U. L. Opara, and K. I. Theron, "Chemical and phytochemical properties and antioxidant activities of three pomegranate cultivars grown in South Africa," Food and Bioprocess Technology, vol. 5, no. 7, pp. 2934-2940, 2012.

[16] V. Dewanto, X. Wu, K. K. Adom, and R. H. Liu, "Thermal processing enhances the nutritional value of tomatoes by increasing total antioxidant activity," Journal of Agricultural and Food Chemistry, vol. 50, no. 10, pp. 3010-3014, 2002.

[17] B. Sun, J. M. Ricardo-da-Silva, and I. Spranger, "Critical factors of vanillin assay for catechins and proanthocyanidins," Journal 
of Agricultural and Food Chemistry, vol. 46, no. 10, pp. 42674274, 1998.

[18] AOAC, Official Methods of Analysis, vol. 1, AOAC, Washington, DC, USA, 15th edition, 1990.

[19] D. Pljevljakušić, K. Šavikin, T. Janković et al., "Chemical properties of the cultivated Sideritis raeseri Boiss. \& Heldr. subsp. raeseri," Food Chemistry, vol. 124, no. 1, pp. 226-233, 2011.

[20] M. M. Özcan, A. Ünver, T. Uçar, and D. Arslan, "Mineral content of some herbs and herbal teas by infusion and decoction," Food Chemistry, vol. 106, no. 3, pp. 1120-1127, 2008.

[21] I. I. Koleva, T. A. Van Beek, J. P. H. Linssen, A. De Groot, and L. N. Evstatieva, "Screening of plant extracts for antioxidant activity: a comparative study on three testing methods," Phytochemical Analysis, vol. 13, no. 1, pp. 8-17, 2002.

[22] R. Re, N. Pellegrini, A. Proteggente, A. Pannala, M. Yang, and C. Rice-Evans, "Antioxidant activity applying an improved ABTS radical cation decolorization assay," Free Radical Biology and Medicine, vol. 26, no. 9-10, pp. 1231-1237, 1999.

[23] V. Ravi, T. S. M. Saleem, S. S. Patel, J. Raamamurthy, and K. Gauthaman, "Anti-inflammatory effect of methanolic extract of Solanum nigrum Linn. Berries," International Journal of Applied Research in Natural Products, vol. 2, pp. 33-36, 2009.

[24] D. Chattopadhyay, G. Arunachalam, A. B. Mandal, T. K. Sur, S. C. Mandal, and S. K. Bhattacharya, "Antimicrobial and antiinflammatory activity of folklore: Mallotus peltatus leaf extract," Journal of Ethnopharmacology, vol. 82, no. 2-3, pp. 229-237, 2002.

[25] L. R. Morse, K. Stolzmann, H. P. Nguyen et al., "Association between mobility mode and c-reactive protein levels in men with chronic spinal cord injury," Archives of Physical Medicine and Rehabilitation, vol. 89, no. 4, pp. 726-731, 2008.

[26] A. Clauss, "Gerinnungsphysiologische schnellmethode zur bestimmung des fibrinogens," Acta Haematologica, vol. 17, no. 4, pp. 237-246, 1957.

[27] H. H. Draper and M. Hadley, "Malondialdehyde determination as index of lipid peroxidation," Methods in Enzymology, vol. 186, pp. 421-431, 1990.

[28] R. Kayali, U. Çakatay, T. Akçay, and T. Altug, "Effect of alphalipoic acid supplementation on markers of protein oxidation in post-mitotic tissues of ageing rat," Cell Biochemistry and Function, vol. 24, no. 1, pp. 79-85, 2006.

[29] H. Aebi, "Catalase in vitro," Methods in Enzymology, vol. 105, pp. 121-126, 1984.

[30] W. F. Beyer Jr. and I. Fridovich, "Assaying for superoxide dismutase activity: some large consequences of minor changes in conditions," Analytical Biochemistry, vol. 161, no. 2, pp. 559-566, 1987.

[31] I. Carlberg and B. Mannervik, "Glutathione reductase," in Glutamate, Glutamine, Glutathione, and Related Compounds, vol. 113 of Methods in Enzymology, pp. 484-490, Elsevier, 1985.

[32] O. H. Lowry, N. J. Rosebrough, A. L. Farr, and R. J. Randall, "Protein measurement with the Folin phenol reagent," The Journal of Biological Chemistry, vol. 193, no. 1, pp. 265-275, 1951.

[33] V. Emanue, V. Adrian, N. A. Sultana, and C. Svetlana, "Antioxidant and antimicrobial activities of ethanol extracts of Cynara scolymus (Cynarae folium, Asteraceae family)," Tropical Journal of Pharmaceutical Research, vol. 10, no. 6, pp. 777-783, 2011.

[34] G. L. D. S. Oliveira, R. A. M. O. Francisco, O. B. A. Vinícius et al., "Evaluation of antioxidant capacity of the aqueous extract of Cynara scolymus L. (Asteraceae) in vitro and in Saccharomyces cerevisiae," African Journal of Pharmacy and Pharmacology, vol. 8, pp. 136-147, 2014.
[35] K. Horiuchi, S. Shiota, T. Hatano, T. Yoshida, T. Kuroda, and T. Tsuchiya, "Antimicrobial activity of oleanolic acid from Salvia officinalis and related compounds on vancomycin-resistant enterococci (VRE)," Biological and Pharmaceutical Bulletin, vol. 30, no. 6, pp. 1147-1149, 2007.

[36] A. Daoud, D. Malika, S. Bakari et al., "Assessment of polyphenol composition, antioxidant and antimicrobial properties of various extracts of Date Palm Pollen (DPP) from two Tunisian cultivars," Arabian Journal of Chemistry, 2015.

[37] D. Krishnaiah, B. Awang, S. Rosalam, and S. M. Anisuzzaman, "Antioxidant activity and total phenolic content of an isolated Morinda citrifolia L. methanolic extract from Polyethersulphone (PES) membrane separator," Journal of King Saud University-Engineering Sciences, vol. 1, pp. 63-66, 2015.

[38] F. Sharififar, G. Dehghn-Nudeh, and M. Mirtajaldini, "Major flavonoids with antioxidant activity from Teucrium polium L.," Food Chemistry, vol. 112, no. 4, pp. 885-888, 2009.

[39] A. Betancor-Fernández, A. Pérez-Gálvez, H. Sies, and W. Stahl, "Screening pharmaceutical preparations containing extracts of turmeric rhizome, artichoke leaf, devil's claw root and garlic or salmon oil for antioxidant capacity," Journal of Pharmacy and Pharmacology, vol. 55, no. 7, pp. 981-986, 2003.

[40] J. Kukić, V. Popović, S. Petrović et al., "Antioxidant and antimicrobial activity of Cynara cardunculus extracts," Food Chemistry, vol. 107, no. 2, pp. 861-868, 2008.

[41] S. Konyalıoğlu, H. Sağlam, and B. Kıvçak, " $\alpha$-Tocopherol, flavonoid, and phenol contents and antioxidant activity of Ficus carica. leaves," Pharmaceutical Biology, vol. 43, no. 8, pp. 683686, 2005.

[42] D. U. Bawankule, P. Trivedi, A. Pal et al., "Protective mechanism of lignans from Phyllanthus amarus against galactosamine/ lipopolysaccharide-induced hepatitis: an in-vivo and in-silico studies," Current Topics in Medicinal Chemistry, vol. 14, no. 8, pp. 1045-1055, 2014.

[43] G. A. Higgs, R. J. Flower, and J. R. Vane, "A new approach to antiinflammatory drugs," Biochemical Pharmacology, vol. 28, no. 12, pp. 1959-1961, 1979.

[44] A. A. Hemmati, H. Kalantari, A. Siahpoosh, B. Ghorbanzadeh, and H. Jamali, "Anti-inflammatory Effect of Hydroalcoholic Extract of the Washingtonia filifera Seeds in CarrageenanInduced Paw Edema in Rats," Jundishapur Journal of Natural Pharmaceutical Products, vol. 10, no. 1, pp. 19-25, 2015.

[45] I. Posadas, M. Bucci, F. Roviezzo et al., "Carrageenan-induced mouse paw oedema is biphasic, age-weight dependent and displays differential nitric oxide cyclooxygenase-2 expression," British Journal of Pharmacology, vol. 142, no. 2, pp. 331-338, 2004.

[46] K. Pundarikakshudu, D. H. Shah, A. H. Panchal, and G. C. Bhavsar, "Anti-inflammatory activity of fenugreek (Trigonella foenum-graecum Linn) seed petroleum ether extract," Indian Journal of Pharmacology, vol. 48, no. 4, pp. 441-444, 2016.

[47] S. Cuzzocrea, G. Costantino, E. Mazzon, B. Zingarelli, A. De Sarro, and A. P. Caputi, "Protective effects of Mn(III)tetrakis (4-benzoic acid) porphyrin (MnTBAP), a superoxide dismutase mimetic, in paw oedema induced by carrageenan in the rat," Biochemical Pharmacology, vol. 58, no. 1, pp. 171-176, 1999.

[48] M. A. Mendall, P. Patel, M. Asante et al., "Relation of serum cytokine concentrations to cardiovascular risk factors and coronary heart disease," Heart, vol. 78, no. 3, pp. 273-277, 1997.

[49] A. Ialenti, A. Ianaro, S. Moncada, and M. Di Rosa, "Modulation of acute inflammation by endogenous nitric oxide," European Journal of Pharmacology, vol. 211, no. 2, pp. 177-182, 1992. 
[50] D. Salvemini, Z.-Q. Wang, D. M. Bourdon, M. K. Stern, M. G. Currie, and P. T. Manning, "Evidence of peroxynitrite involvement in the carrageenan-induced rat paw edema," European Journal of Pharmacology, vol. 303, no. 3, pp. 217-220, 1996.

[51] E. E. S. Schapoval, M. R. Winter De Vargas, C. G. Chaves, R. Bridi, J. A. Zuanazzi, and A. T. Henriques, "Antiinflammatory and antinociceptive activities of extracts and isolated compounds from Stachytarpheta cayennensis," Journal of Ethnopharmacology, vol. 60, no. 1, pp. 53-59, 1998.

[52] E. Aleo, R. Ricci, S. Passi, and S. A. Cataudella, "Novel cyt-H2O2-chemiluminescenes assay for measuring the reducing/antioxidant capacity on hydrophilic and lipophilic antiooxindants and biological samples," Progress in Nutrition, vol. 3, pp. 154-182, 2005.

[53] E. Mazzon, E. Esposito, R. Di Paola et al., "Effects of verbascoside biotechnologically produced by Syringa vulgaris plant cell cultures in a rodent model of colitis," Naunyn-Schmiedeberg's Archives of Pharmacology, vol. 380, no. 1, pp. 79-94, 2009.

[54] E. J. Middleton, "Effect of plant flavonoids on immune and inflammatory cell function," Advances in Experimental Medicine and Biology, vol. 439, pp. 175-182, 1998.

[55] J. Baumann, F. Von Bruchhausen, and G. Wurm, "Flavonoids and related compounds as inhibitors of arachidonic acid peroxidation," Prostaglandins, vol. 20, no. 4, pp. 627-639, 1980.

[56] M. D. Dos Santos, M. C. Almeida, N. P. Lopes, and G. E. P. De Souza, "Evaluation of the anti-inflammatory, analgesic and antipyretic activities of the natural polyphenol chlorogenic acid," Biological and Pharmaceutical Bulletin, vol. 29, no. 11, pp. 22362240, 2006. 


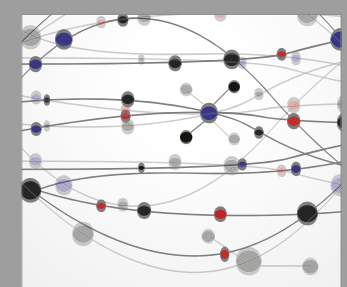

The Scientific World Journal
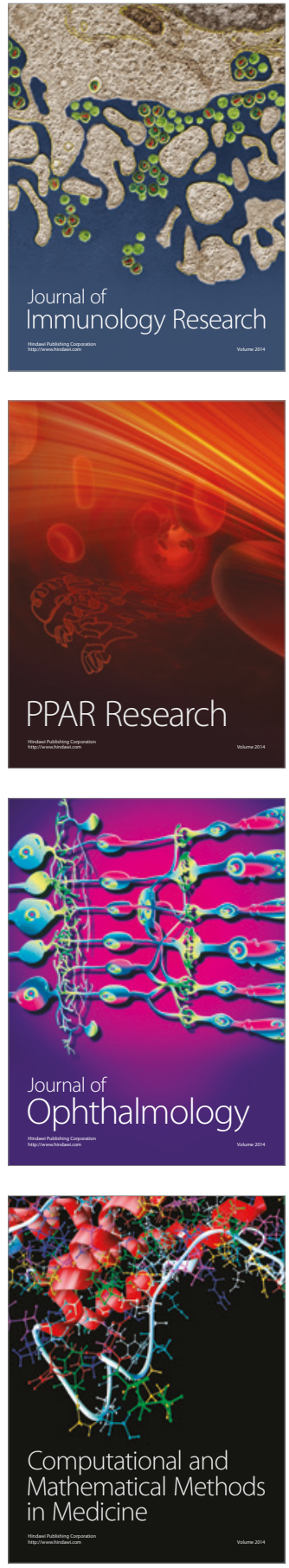

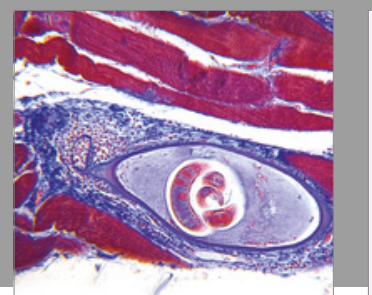

Gastroenterology Research and Practice
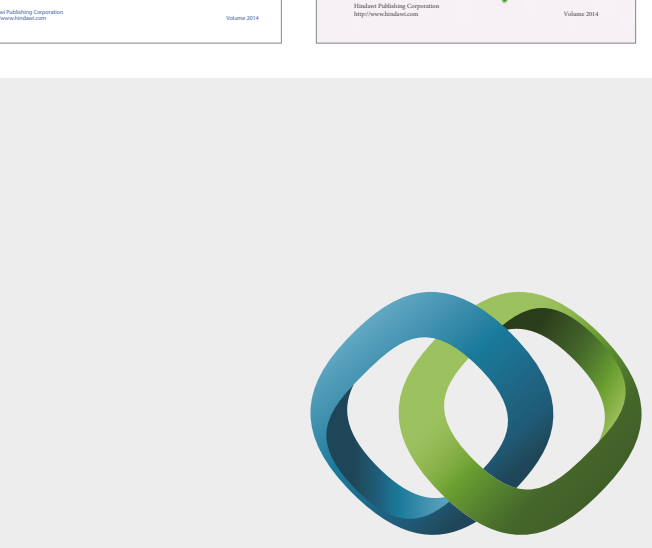

\section{Hindawi}

Submit your manuscripts at

https://www.hindawi.com
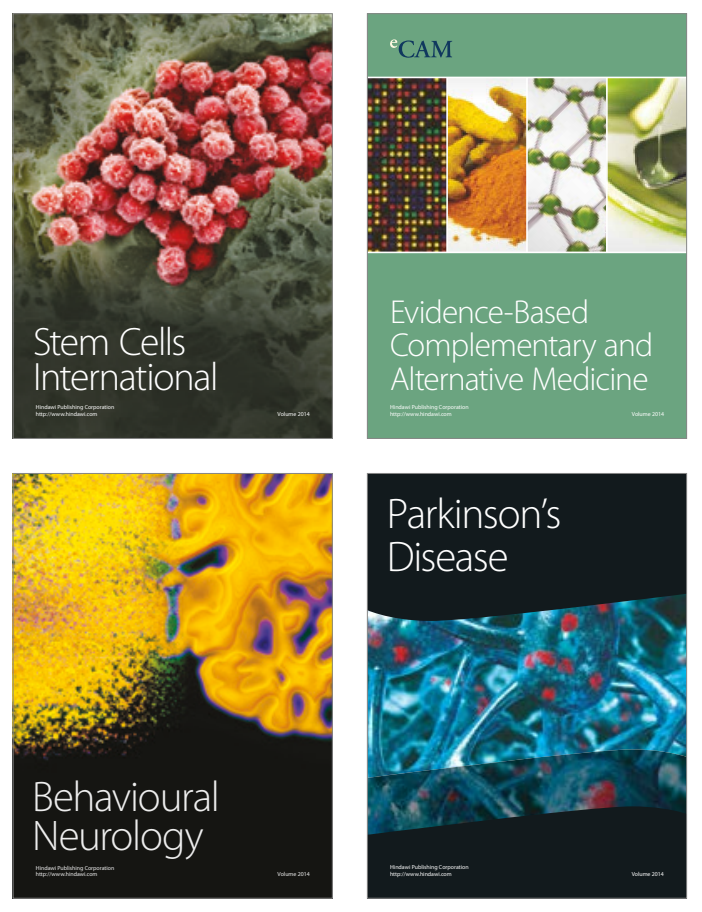
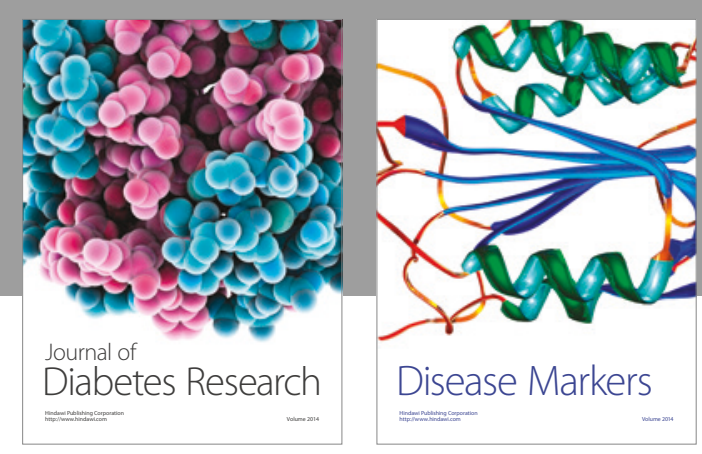

Disease Markers
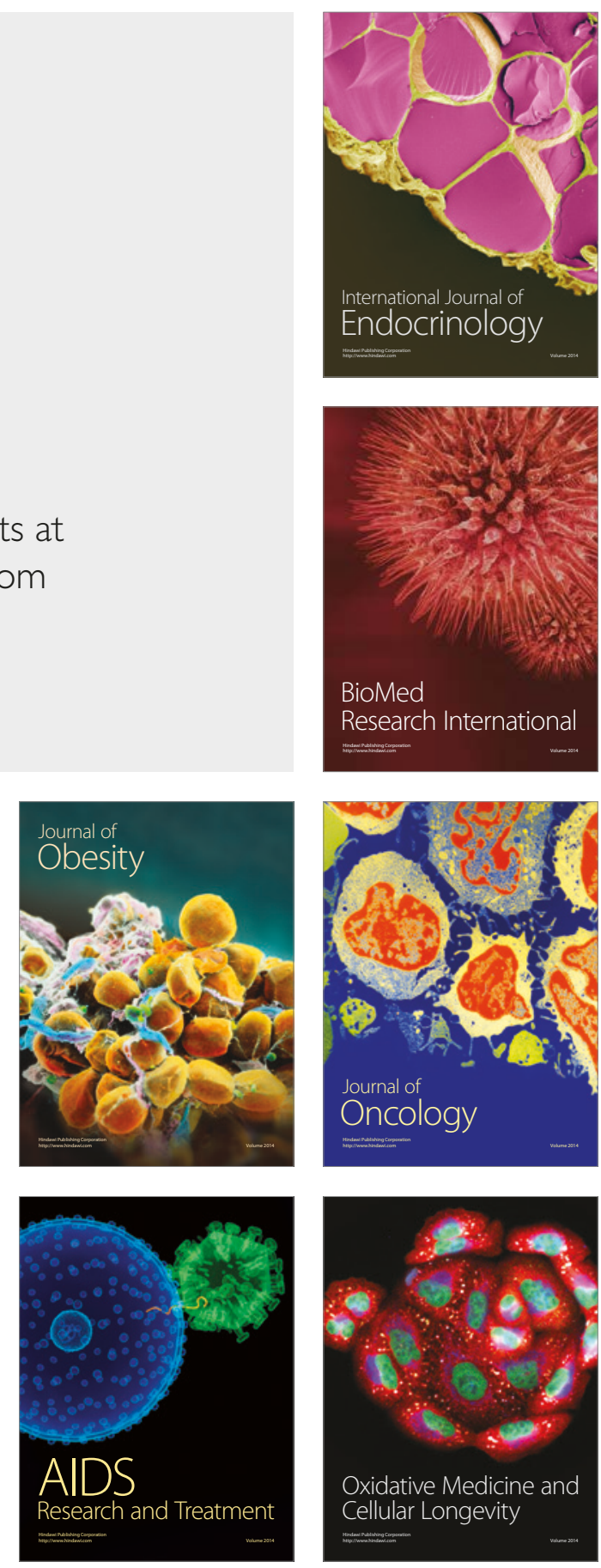